\title{
Determinants of adolescents reproductive health service utilization in Ethiopia: a systematic review of quantitative evidence
}

This article was published in the following Dove Press journal:

Adolescent Health, Medicine and Therapeutics

\author{
Gelila Abraham' \\ Kiddus Yitbarek' \\ Sudhakar Narayan Morankar² \\ 'Health Policy and Management \\ Department, Jimma University, Jimma, \\ Ethiopia; ${ }^{2} \mathrm{Health}$ Behavior and Society \\ Department, Jimma University, Jimma, \\ Ethiopia
}

\begin{abstract}
Purpose: Adolescents in Ethiopia face many health problems which emanate from low knowledge and awareness of their reproductive health $(\mathrm{RH})$, though there are additional factors contributing to the problem. Provision of adequate, friendly, and quality RH services to this group of young people is vital to have healthy and productive generation. This systematic review aimed to assemble the top obtainable evidence for the determinants of adolescent RH services utilization in Ethiopia.
\end{abstract}

Methods: Systematic review of literature searches in major databases, MEDLINE, CINAHL, EMBASE, and Popline was conducted. English language articles published from 2010 onwards were sought. Socio-demographic and behavioral related outcomes were our interest. Fixed effect model with mantel Haenszel method was used to conduct meta-analysis using Revman5 software. Records were assessed for eligibility by two independent reviewers, with a third reviewer resolving disagreements.

Result: Four community-based cross-sectional studies were included in the review. Results of the meta-analysis showed that adolescents whose educational level was primary were $57 \%$ less likely to use RH services than adolescents whose educational level was secondary and above. In-school adolescents were 2.39 more likely to utilize Family Planning services than adolescents who were out-of-school. Moreover, adolescents who ever discussed on RH issues with relatives/family/health workers were 3.63 more likely to utilize the services than adolescents who did not discuss with anyone else.

Conclusion: We found adolescents' educational level; schooling status and ever discussion on RH issues were associated with RH service utilization in Ethiopia. Health information/education should be given in a regular manner to adolescents in schools and out of school on the availability and need for RH services. Developing the culture of discussion on RH issues within the community may help adolescents to be aware and utilize the available services.

Keywords: adolescents, Ethiopia, factors, reproductive health, utilization

\section{Introduction}

Adolescence, the second span of a lifetime, is a period in which an individual go through main physical and psychological deviations and also it is a period of opportunity, but also one of danger. ${ }^{1}$ Nowadays the world has 1.2 billion adolescents in which almost $90 \%$ live in low-income countries. ${ }^{2}$ These young people account for $15 \%$ of the disease and injury load worldwide, and more than one million die annually, mainly from avoidable causes. ${ }^{3}$

\footnotetext{
Correspondence: Gelila Abraham Health Management and Policy Department Jimma University, PO Box 378, Jimma, Ethiopia

Tel +251932448617

Email abrahamgelila7@gmail.com
} 
Although adolescent health is a global health priority, information on the degree of health problems among this age group leftovers weak. ${ }^{4}$ The issue of the sexual and reproductive health (SRH) of adolescents is a worry as a result of unplanned and/or unintentional pregnancy, HIV/ AIDS pandemic, and other sexually transmitted illnesses. ${ }^{5}$ These had negative social and demographic impacts. Proofs from Sub-Saharan African countries show high occurrence rates of sexual intercourse; rare use of condoms and other contraceptives; high prevalence of two or more lifetime sexual partners among young people., ${ }^{6,7}$

Sub-Saharan Africa, is an area where teenagers make up the highest share of the population, with entirely $23 \%$ of the section's population aged 10-19. ${ }^{2}$ In most nation-states of this section, youth come across substantial impairments to get SRH services and to finding active, up-to-date contraception and condoms to keep from sexually transmitted illnesses, including HIV. ${ }^{8}$ Consequences of adolescents' health snags, do not end in this age group; rather it may persevere to their upcoming lifetime. Regarding this, literature established that numerous health glitches and considerable of the dangerous behavior that causes future health problems initiate throughout teenage years. ${ }^{9}$ Thus promoting healthy practices during adolescence to well protect this age group from risks will safeguard longer, more creative lived for many. ${ }^{10}$

Ethiopia has a young population with adolescents and youth (10-24 years) accounting for 33.8\%. ${ }^{11}$ Among these, $85 \%$ of them reside in countryside areas, where education levels tend to be much lesser, predominantly for girls. ${ }^{12}$ The adolescents' health difficulties in the state include; SRH, malnutrition, substance abuse, non-communicable diseases, mental illness, injuries, and violence. ${ }^{13}$ Thus, adolescents in Ethiopia face a high burden of morbidities and mortalities from multiple contributors. In the country, about $64 \%$ of young girls start sexual intercourse before 18 years, among whom $26 \%$ starts before 15 years. ${ }^{14}$

Though the minimum legal age at marriage for both sexes is 18 years, about $40 \%$ of girls in Ethiopia marry earlier. ${ }^{14,15}$ Accordingly, adolescent pregnancy ratio is $12 \%$, one of the uppermost in the world and furthermore, around $34 \%$ of pregnancies among adolescents aged 15-19 years in the country is accidental; ${ }^{15}$ which is the main cause for induced abortion and following difficulties as well as snowballing number of abandoned children and orphans. Except they hold forth, the reproductive health (RH) snags fronting Ethiopian youth loom to delay the country's progress even more and bring greater unpredictability to a country previously suffering from high levels of joblessness, food uncertainty, and extensive life-threatening poverty. ${ }^{6}$

The WHO recommends that to make advancement toward universal health coverage, ministries of health, and the health sector more generally must convert how health systems respond to the health need of adolescents. ${ }^{16}$ However, evidence from both high- and low-income countries shows that adolescents and young adults face many barriers which prevent their use of SRH services. ${ }^{17-21}$

In Sub-Saharan Africa, limited access to education and to economic resources symbolizes the lives of young people. Adolescent's limited access to resources seriously challenges their health and healthcare-seeking behavior. The overloaded and under-financed public health and education systems that are in place are often incapable to deliver friendly and high-quality services to young people. Thus, major obstacles commonly prevent African adolescents from gaining immediately desirable reproductive and sexual health services. ${ }^{8,22}$ Evidences from different countries show that adolescents have the knowledge or had ever heard about at least one of the RH services, though the rate of utilization was very low. ${ }^{23-25}$ The rate of adolescent $\mathrm{RH}$ service utilization was as low as $51 \%$ in Nigeria $^{26}$ and $38 \%$ in Malawi. ${ }^{27}$

The mainstream of adolescents in Ethiopia stayed not using reproductive and sexual health services. The subjects of privacy, a terror of revealing health worries, low approachability to services, non-friendliness of existing services, and traditional taboo were among the principal reasons stated by adolescents in the country. Besides, studies conducted in several parts of the country revealed that; most adolescents have the information and knowledge regarding SRH. However, utilization is very low even in urban settings of the country ranging from $21 \%$ to $38 \%{ }^{28-30}$ moreover the rate of SRH services utilization was as low as only $2 \%$ in rural parts of the country. ${ }^{31}$ Issues alike; age, ways of communication, knowledge, parent, and peer discussion on SRH subjects were found to be related with the utilization of SRH services. They had also revealed that parental disapproval, pressure from partners and low educational level were among the Detroiters to utilize the services. ${ }^{31-32}$

Understanding the barriers of adolescent RH service utilization is critical to formulating effective policies and programs for combating ill health because of slight use of the services in Ethiopia. Lessons from the different locations of the country specified that utilization of adolescent 
RH services utilization was very low even in the urban settings. ${ }^{32-34}$ It is important to synthesize the findings of these primary studies to determine the determinants of $\mathrm{RH}$ service utilization. Through a primary search conducted in January 2018, in PubMed and CINAHL, we did not find any systematic review published within the last 3 years. Therefore, this systematic review was aimed to search, critically appraise, synthesize and present the evidence on determinants of RH service utilization among adolescents in Ethiopia. The review question was: What is the best available evidence on the determinants of RH service utilization among adolescents living in Ethiopia?

Ultimately, the findings of this review will be used to update service planners and implementers in a way that adolescents will benefit.

For this review, the following operational definition was used;

- Utilization of Reproductive Health services: The utilization of at least one of SRH services provided to adolescents which includes counseling, information and health education, family planning services, HIV testing, diagnosis and treatment of sexually transmitted illnesses, antenatal, delivery ,and postnatal care services.

\section{Methods}

\section{Search strategy}

A three-stage comprehensive search strategy was used to identify all relevant published and grey literature. First, an initial search of databases MEDLINE (via PubMed), CINHAL, EMBASE, and Popline were performed to identify relevant keywords and search terms. This was followed by a detailed second search by means of all recognized keywords and index terms across major databases. Finally, the lists of reference or bibliographies of all identified articles were checked manually for articles of interest.

A hand search of the reference lists of studies did not find any new studies to be included in the review. An electronic search was led through PubMed, MEDLINE, CINHAL, EMBASE, and Popline. For practical consideration, only fulltext reports that are available electronically to the systematic review team were retrieved. Research conducted after the introduction of the tools to implement the national standards for adolescent and youth-friendly RH services was considered. Thus, literature published from 2010 G.C onwards was searched and only papers published after this time were included in the review.

Keywords for the first search focused on utilization of adolescent RH services and factors associated. Results from this initial search informed subsequent searches until data saturation is reached. The final selection was informed by the agreed Population Intervention Comparator Outcome questions. These searches aimed to identify primary studies assessing determinants of adolescents' RH service utilization. Moreover, keywords for study designs aimed to identify the highest quality evidence about each phenomenon. Initial search terms for both databases and the number of kept records from those search results are provided in Appendix I and studies retrieved for detailed examination are presented in Appendix II.

\section{Inclusion criteria}

As the focus of interest for the review was the determinants of RH service utilization among adolescents, we have considered any quantitative evidence from crosssectional studies that have identified determinants of RH service utilization. Thus, quantitative studies reporting on factors that affect the utilization of $\mathrm{RH}$ services among adolescents living in Ethiopia which were conducted both within and outside schools were considered for inclusion in the review. Moreover, the review well-thought-out adolescents within the age group 10-19 years who live in the country irrespective of urban and rural setting. The exposures of interest were socio-demographic characteristics of adolescents and behavioral related factors. Meanwhile, the outcomes were RH service utilization reported in the form of ever use of one of the RH services listed above on the operational definition. The main outcome measures anticipated include:

1. Socio-demographic related outcome measures: Educational level and schooling status

2. Behavioral related factor: Ever discussion on $\mathrm{RH}$ issues with family/relatives/health workers

\section{Methodological quality assessment}

All studies were assessed for eligibility by reading titles, abstracts and full texts, then, studies nominated for repossession were evaluated by two independent reviewers for their methodological cogency preceding to inclusion in the systematic review. A standardized critical appraisal tools from the Joanna Briggs Institute (JBI) was used for this purpose (Appendix IV). 


\section{Data extraction}

A standardized data extraction tool from Joanna Brigs Institute (Appendix V) was used to extract data from papers included in the systematic review. This was carried out independently by two researchers, and incase the results did not match, the third researcher resolved the differences.

\section{Data synthesis}

Quantitative papers were pooled in Review manager (Revman 5.1) for statistical meta-analysis. Effect sizes expressed as odds ratio and their $95 \%$ confidence intervals were calculated for analysis. Heterogeneity was measured statistically by the standard chi-square test and explored using subgroup analyses for all studies included for the final review.

\section{Results}

\section{Description of studies}

Four hundred and three (403) potentially relevant papers were identified by literature search. After removing duplicates (49 papers) and unrelated titles (321 papers), 33 studies were left for screening (Appendix). After an abstract review of those papers, twenty-two (22) of them were excluded because of the difference in outcome and population of interest. Then, eleven (11) papers were retrieved for detailed examination and after full-text review of those papers, seven papers were excluded because of the nature of the study (pure qualitative) and an unintended population of interest. Finally, full texts of the remaining four papers were selected for methodological quality assessment using JBI critical appraisal tools. All appraised papers met the inclusion criteria and were included in the review. The list of papers not selected for retrieval is presented in Appendix III. The details of the counted in studies are presented in Appendix VI. All studies that examined the utilization of RH services and its determinants amongst adolescents (10-19 years) were included for the final review. Below is the PRISMA presentation for the selection of studies (Figure 1).

\section{Characteristics of included studies}

Four cross-sectional primary studies ${ }^{35,36}$ were used to find the determining factors of adolescent RH service utilization in Ethiopia. These studies reported; the level of education (for both adolescents and their parents), co-residence with parents, risk vulnerability, lack of basic information including know where service provided, low parent-adolescent communication, discussion of SRH services especially with health workers as determinants of adolescent RH service utilization. One study was included in the review though it included young people within the age group 10-24, because of nearly three fourth participants were adolescents (10-19 years) and the review team believed including is advantageous to get a better evidence, as the other studies did not participate adolescents 10-14 years old. A summary of the main findings from each included study is presented in Appendix VII.

\section{Methodological quality assessment}

Four cross-sectional descriptive primary studies ${ }^{35,36}$ were included for methodological quality assessment and two of them scored seven out of nine and the two scored nine out of nine (Table 1). The participant sample was representative in which criteria for inclusion were clearly identified. Comparisons were made among groups and appropriate statistics was made in all the four included studies. The critical appraisal tool is presented in Appendix IV.

\section{Results of meta-synthesis/analysis}

The drive of this meta-analysis was to identify the determinants of RH service utilization among adolescents in Ethiopia, by using proportions, not specific estimates of the risk factors for the outcome variable measured in primary studies ${ }^{35,36}$ to calculate the pooled effect sizes. Fixed effects meta-analysis model was used. ${ }^{37}$

Heterogeneity between the studies was measured using the $\chi^{2}$ test at a statistically significant level of $p<0.05$. The percentage of the variability in effect estimates between the studies that are due to heterogeneity was assessed using the $\mathrm{I}^{2}$ test. Pooled estimates (pooled odds ratio) was used to show the level of strength between outcome and independent variables. In this meta-analysis, all studies having similar independent variables were combined. A pooled odds ratio was used as a measure of effect size for combined studies. The Mantel Haenszel statistical method was used to calculate effect sizes and forest plots for the meta-analyses are shown in Figures 2-5.

\section{Educational level of adolescents}

All included studies ${ }^{35,36}$ reported adolescents' level of education as a predictor variable to $\mathrm{RH}$ service utilization. Data from the studies were combined in a meta-analysis. For this variable the heterogeneity is found to be $\chi^{2}=1.54$, $p=0.67$ and no heterogeneity was not found between the studies $\left(\mathrm{I}^{2}=0 \%\right)$. In all studies, adolescents whose educational level was secondary and above were reported to utilize RH service better than adolescents whose educational level was primary. This difference in RH service 
utilization between adolescents of primary and secondary and above educational status showed a statistically significant difference when they are pooled in the meta-analysis as shown on the forest plot (Figure 2). Adolescents whose education level was primary were $57 \%$ less likely to utilize RH services than adolescents whose education level was secondary and above (Pooled $\mathrm{OR}=0.43,95 \% \mathrm{CI}=0.32$, $0.58, P$-value $<0.00001)$.

\section{Schooling status of adolescents}

Two studies ${ }^{38,39}$ reported that schooling status of adolescents as a predictor variable to family planning (FP) service utilization. Data from both studies were combined in a metaanalysis. For this variable the heterogeneity is found to be $\chi^{2}=2.48, p=0.12$ and moderate heterogeneity was found between the studies $\left(\mathrm{I}^{2} 60 \%\right)$. This difference can be because of the small sample size of participants of the study. Both studies reported that in-school adolescents better utilize FP service than adolescents who are out of school. This difference in FP service utilization between in-school adolescents and out-of-school adolescents showed a statistically significant difference when they are pooled in the meta-analysis as shown on the forest plot in Figure 3. Adolescents who were in-school were 2.39 more likely to use FP services than adolescents who were out-of-school (Pooled OR=2.39, 95\% CI $=1.58,3.64, P$-value $<0.0001)$.

The above two studies ${ }^{38,39}$ also reported the schooling status of adolescents as a predictor to voluntary counseling and testing (VCT) service utilization. For this variable, the heterogeneity is found to be $\chi^{2} 0.43, p=0.51$ and no heterogeneity was found between the studies $\left(\mathrm{I}^{2} 0 \%\right)$. Both studies reported that in-school adolescents better utilize VCT service than adolescents who are out of school. This difference in VCT service utilization between inschool adolescents and out-of-school adolescents, however, did not show a statistically significant difference when they are pooled in the meta-analysis as shown on the forest plot on Figure 4. (Pooled OR=1.17, 95\% $\mathrm{CI}=0.90,1.52, P$-value $=0.25)$.

\section{Ever discussion on $\mathrm{RH}$ issues}

All included studies ${ }^{35,36}$ reported ever discussion on $\mathrm{RH}$ issues as a predictor variable to $\mathrm{RH}$ service utilization. Data from these three primary studies were combined in a meta-analysis. For this variable the heterogeneity is found to be $\chi^{2}=7.89, p=0.05$ and moderate heterogeneity was found between the studies $\left(\mathrm{I}^{2}=62 \%\right)$. This difference between studies might be explained by the difference

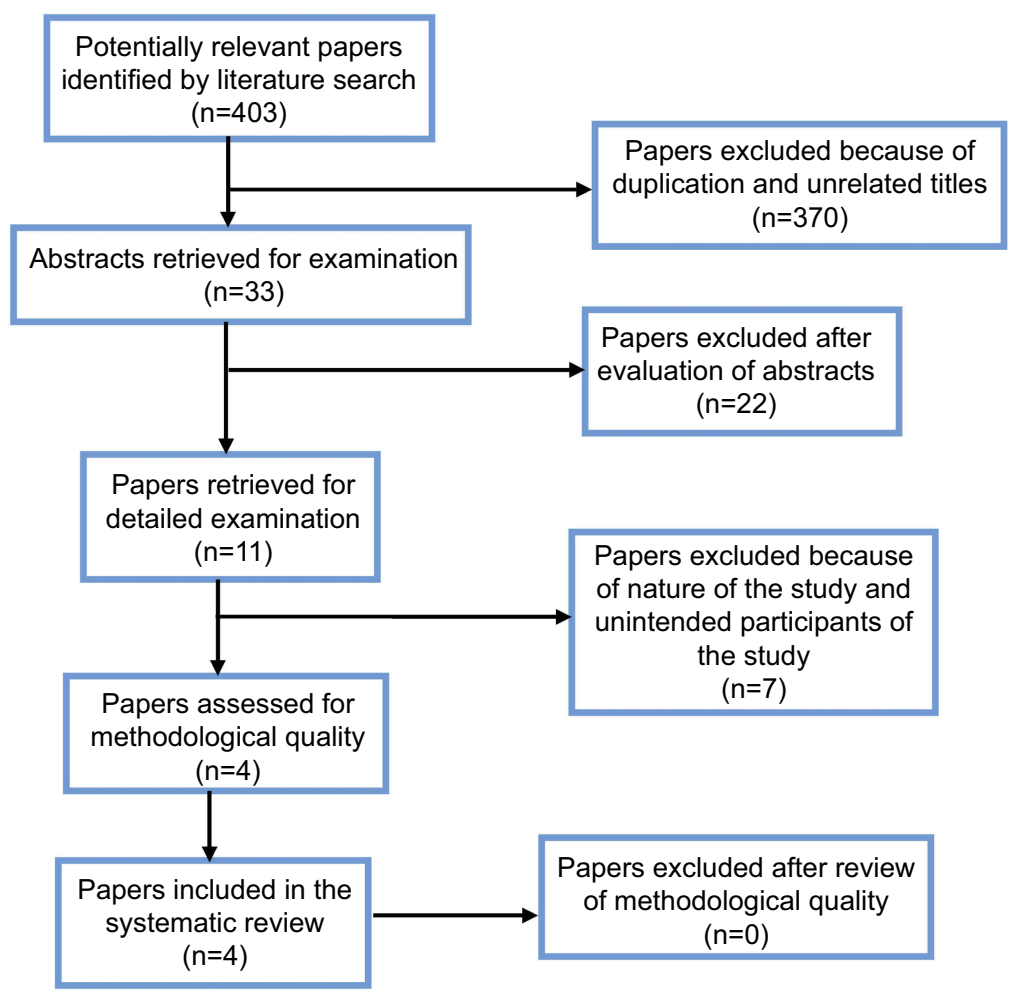

Figure I Schematic presentation of the study selection process. 
between the studies regarding the small sample size of individual studies. In three studies, adolescents who ever discussed on FP issues with either their relatives/family/ health worker were reported to utilize FP service better than adolescents who did not discuss on FP issue with anyone else. In one study, adolescents who ever discussed on $\mathrm{RH}$ issues with either their relatives/family/health worker were reported to utilize RH service more than adolescents who did not discuss on $\mathrm{RH}$ issue with anyone else. This difference between RH service utilization between adolescents who ever discussed on RH issues and did not discuss showed a statistically significant difference when they are pooled in the meta-analysis as shown on the forest plot (Figure 5). Adolescents who ever discussed on $\mathrm{FP} / \mathrm{RH}$ issues with relatives/family/ health workers were 3.63 more likely to use FP/RH services than adolescents who did not discuss on $\mathrm{FP} / \mathrm{RH}$ issues with anyone else. (Pooled $\mathrm{OR}=3.63$, 95\% $\mathrm{CI}=2.37$, 5.57, $P$-value $<0.00001)$.

\section{Discussion}

This systematic review was aimed to explore the evidence about the determinants of RH service utilization among adolescents (10-19 years) in Ethiopia. Four studies met our inclusion criteria and were considered of sufficient methodological quality to be counted in the review. All of the comprised studies were descriptive cross-sectional and thus it should be considered that there is a most likely risk of bias as compared to other study designs, such as experimental.

\section{Agreements and disagreement with other studies}

This systematic review has found that adolescents whose educational level was primary were less likely to utilize RH services than adolescents whose educational level was secondary and above. This finding is consistent with the primary studies that reported being $1-8^{\text {th }}$ grade have

Table I Results of critical appraisal for each of the included cross-sectional studies

\begin{tabular}{|c|c|c|c|c|c|c|c|c|c|c|}
\hline Studies & Q I & Q2 & Q3 & Q4 & Q5 & Q6 & Q7 & Q8 & Q9 & Total score \\
\hline Abajobir et al $2014^{35}$ & $Y$ & $\mathrm{Y}$ & $Y$ & $Y$ & U & $Y$ & $\mathrm{Y}$ & $Y$ & $N$ & $7 / 9$ \\
\hline Gebresilassie et al $2015^{38}$ & Y & Y & Y & $Y$ & $Y$ & Y & $\mathrm{Y}$ & Y & Y & $9 / 9$ \\
\hline Feleke et al $2013^{39}$ & Y & Y & $Y$ & $Y$ & $Y$ & $Y$ & $Y$ & $Y$ & $Y$ & $9 / 9$ \\
\hline Mustafa et al $2017^{36}$ & $Y$ & $Y$ & $Y$ & $Y$ & $Y$ & Y & U & $Y$ & $u$ & $7 / 9$ \\
\hline
\end{tabular}

Notes: QI - Was the sample frame appropriate to address the target population?

Q2 - Were sampled in an appropriate way?

Q3 - Was the sample size adequate?

Q4 - Were the study subjects and the setting described in detail?

Q5 - Was the data analysis conducted with sufficient coverage of the identified sample?

Q6 - Were valid methods used for the identification of the condition?

Q7 - Was the condition measured in a standard, reliable way for all participants?

Q8 - Was there

Q9 - Was the response rate adequate, and if not, was the low response rate managed appropriately?

Abbreviations: Y, yes; N, no; U, unclear.

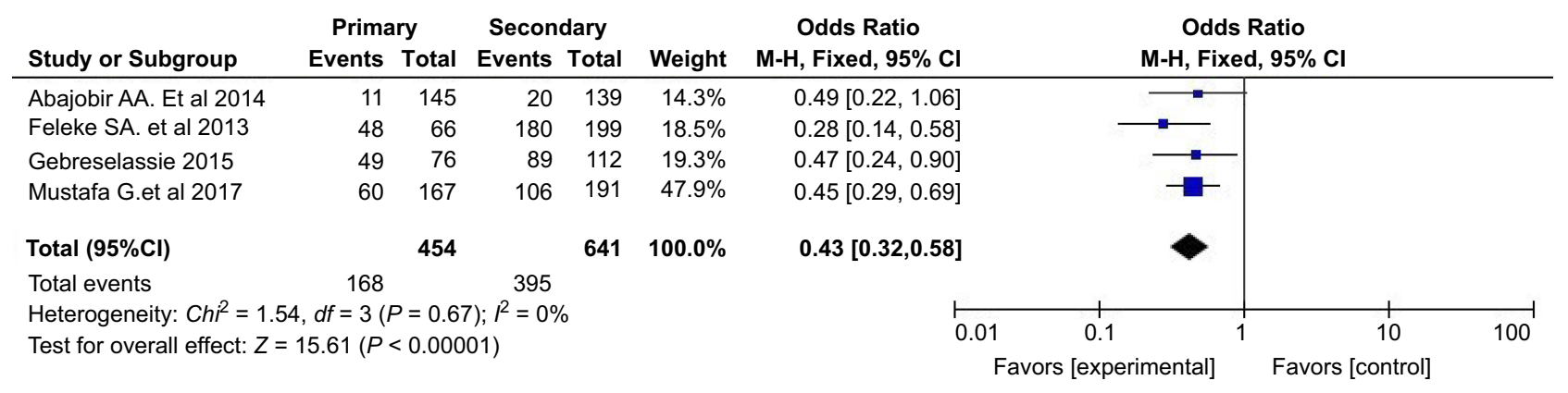

Figure 2 Adolescents whose educational level was primary were less likely to utilize RH services than adolescents whose educational level was secondary and above. Abbreviation: $\mathrm{RH}$, reproductive health. 


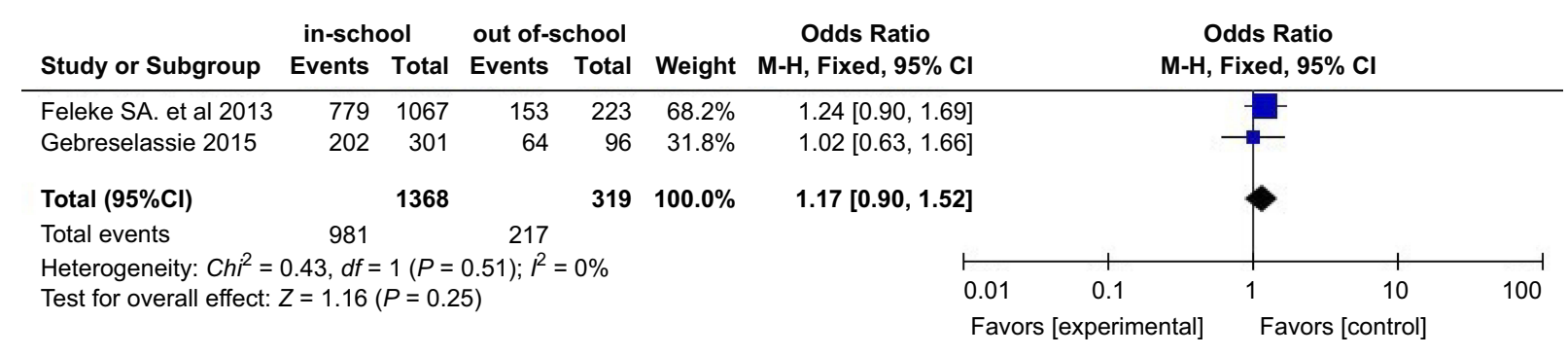

Figure 4 There was no significant difference in VCT service utilization among in-school and out of adolescents.

Abbreviation: VCT, voluntary counceling testing.

negatively affected youth $\mathrm{RH}$ services $[\mathrm{COR}=0.50,95 \%$ CI $(0.33,0.76)]^{32}$ and young people who reached primary level of education were $74 \%$ less likely to utilize $\mathrm{RH}$ service than their counterparts [AOR $(95 \%$ CI):0.26 $(0.12,0.53)] .{ }^{24}$ This could be explained as adolescents in the higher grades may have the knowledge on the services and get an access to use in addition to their maturity as secondary school students are older than primary school students. However, this finding was in contrast to another primary study that did not show the association of adolescents educational level with RH service utilization. ${ }^{40}$

The review also found a significant difference in FP service utilization among adolescents by their schooling status. The review indicated that in-school adolescents were more likely to use FP services than adolescents who were out-of-school. This could be potentially explained by in-school adolescents may have a better opportunity to hear and know about RH services as there will be clubs in their schools than adolescents who were not students. Moreover, it is an implication for the Ministry of Education to work on the accessibility of schools particularly for rural adolescents, as education has a direct relation with the wellbeing of a community. This finding was consistent with other primary studies in the country. ${ }^{32,40}$ On the contrary, this systematic review did not show a statistical significant difference on VCT service utilization between in-school and out-of-school adolescents. This finding is inconsistent with primary study ${ }^{40}$ which reported schooling status to have an association with VCT service utilization.

Moreover, this systematic review showed that adolescents who ever discussed on RH issues whether with one or more of their nearby individuals like, family, relatives, and health care workers were more likely to utilize $\mathrm{RH}$ services than adolescents who never ever discuss on RH issues with anyone. This finding is consistent with other studies elsewhere, which reported ever discussion on RH issues was an independent predictor for RH service utilization and showed adolescents who ever discussed on RH issues with family/relative/health workers were more likely to utilize RH services than adolescents who did not discuss the issue with anyone else. ${ }^{24,34}$ This implies, adolescents who discuss RH issues with family/relative/ health workers would have a better knowledge and awareness about RH services and thus would be motivated to use the services. ${ }^{24}$ In contrary, finding of this review was not supported by the primary study ${ }^{40}$ which reported that adolescents who never discussed on VCT services were significantly more likely to use the service than adolescents who has discussed. This difference was explained by adolescents who have information and have discussed VCT with different individuals may not think they need

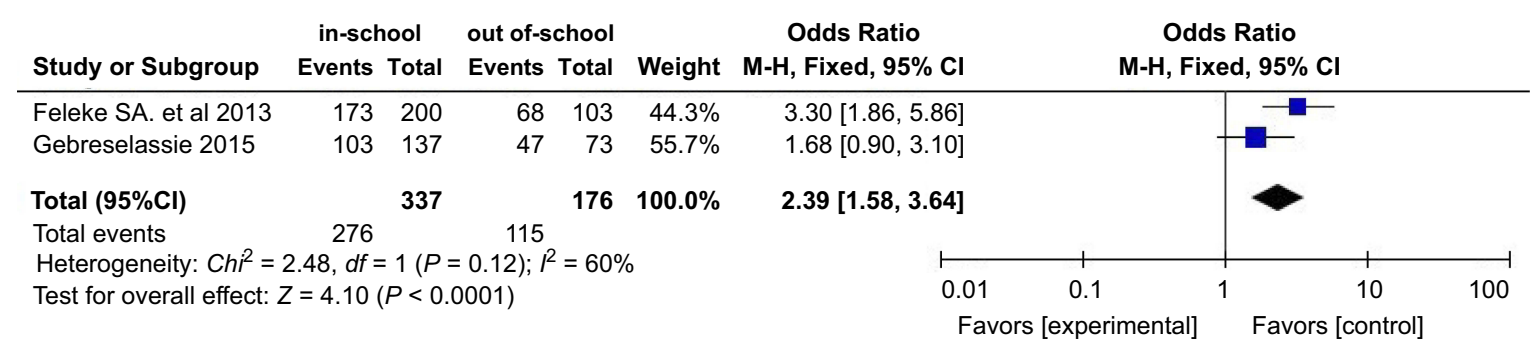

Figure 3 Adolescents who were in school were more likely to utilize FP service than adolescents who were out of school.

Abbreviation: FP, family planning. 


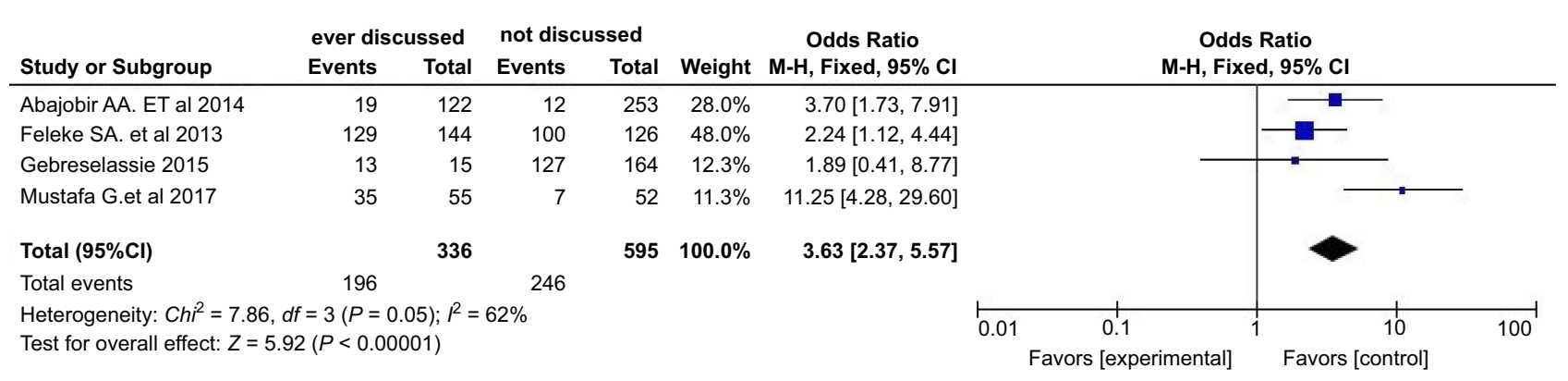

Figure 5 Adolescents who ever discussed on FP/RH issues with relatives/family/health workers were more likely to utilize $\mathrm{FP} / \mathrm{RH}$ services than adolescents who did not discuss with anyone else.

Abbreviations: FP, family planning; $\mathrm{RH}$, reproductive health.

VCT service because they perceive a low risk, which shows there is a gap in continuity of discussion, communication, and information to bring behavioral change.

\section{Potential biases in the review process}

Risk of biases was assessed during the review process. Regarding the selection of subjects, the selection was random in all the included studies. ${ }^{35,36}$ All studies were from Ethiopia, as the focus of the review was Ethiopian adolescents 10-19 years. Three of the studies included adolescents aged $15-19^{36-38}$ and one study included young people 10-24 years, ${ }^{35}$ but all studies utilized similar outcome variables (RH services, specifically FP and VCT). All studies employed a community-based cross-sectional study design.

The validity of all included studies was assessed prior to inclusion for each study and accepted based on JBI critical appraisal tool. The risk of confounding was also assessed for possible confounders for all included primary studies ${ }^{35,36}$ by conducting logistic regressions. Sampling error, in primary studies, was also reduced by taking representative samples. The presence of differences between the studies regarding the small sample of individual studies and being studies from rural and urban settings might explain the moderate heterogeneity observed in this meta-analysis.

\section{Strengths and limitation of the review}

The comprehensive search undertaken and quantifying the evidences using one of the best software for meta-analysis can be taken as the strengths of the review.

A potential limitation of the present systematic review might be only full-text articles published in the English language were included in the review and therefore key articles possibly published in other languages on the area were not considered.

\section{Conclusion}

We found an educational level, schooling status, and ever discussion on $\mathrm{RH}$ issues with family/relatives/health workers determined RH service utilization among adolescents in Ethiopia. Being in school and having secondary and above educational status were potential factors which make adolescents knowledgeable and aware of RH services, which in turn increase the likelihood of using $\mathrm{RH}$ services. Moreover, discussion on $\mathrm{RH}$ issues potentially increase knowledge and awareness among adolescents and hence motivate them to utilize the available $\mathrm{RH}$ services. Addressing all adolescents in need of RH services where ever they are and encouraging them to discuss $\mathrm{RH}$ issues at least with their beloved ones is recommended to have aware and utilizer adolescents who will, in turn, be healthy and machineries for their country's development.

\section{Implications for practice}

Health care workers and any other responsible bodies should work on how to develop the culture of discussing $\mathrm{RH}$ issues in the community. This should begin with a discussion of adolescents with their family and relatives staring from their childhood. School-based interventions will also help adolescents to be aware of the issue starting from the primary educational level, for those adolescents in-school. Primary health care workers should address adolescents where they are in delivering the services, particularly for adolescents in rural areas who are out-ofschool. 


\section{Implications for research}

Further research utilizing more robust experimental methods would help to advance the findings of this review. Moreover, studies assessing the utilization of RH services among different sub-groups of adolescents will help to have a focused area which will provide a secular finding for each of the categories.

\section{Abbreviations}

FP, family planning; BI, Joanna Briggs Institute; PICO, population intervention comparator outcome; $\mathrm{RH}$, reproductive health; RHS, reproductive health service; SRH, sexual and reproductive health; VCT, voluntary counseling, and testing.

\section{Acknowledgment}

We acknowledge the JBI-Jimma University Collaborating Centre for providing the training on systematic reviews.

\section{Disclosure}

The authors report no conflicts of interest in this work.

\section{References}

1. World Health Organization. Strengthening the Health Sector Response to Adolescent Health and Development. 2018. Available from: http://www.searo.who.int/entity/child_adolescent/topics/adoles cent_health/en/. Accessed September 17, 2018.

2. United Nations Children's Fund (UNICEF). Progress for Children: A Report Card on Adolescents. 2012. Available from: http://www. icyrnet.net $/$ index.php?page $=$ news\&lang $=$ en\&id $=234 . h t m l . ~ A c c e s s e d$ September 20, 2018

3. Rosen JE. Adolescent Health and Development (AHD): A Resource Guide for World Bank Operations Staff and Government Counterparts. Washington, DC: The International Bank for Reconstruction and Development/The World Bank; 2004.

4. World Health Organization. Child and Adolescent Health and Development: Progress Report. Geneva, Switzerland: Department of Child and Adolescent Health and Development; 2006.

5. World Health Organization. Introduction to Adolescence \& to Adolescent Health: Training Course in Sexual and Reproductive Health Research. Geneva; 2012

6. United States Agency for International Development. Assessment of Youth Reproductive Health Programs in Ethiopia. United States of America; 2004.

7. Ministry of Planning and Development, And Sports the Ministry of Youth Development. Carrying Malawi Forward: Investing in Sexual and Reproductive Health for Young People. Malawi; 2015.

8. Moya C. Creating youth-friendly sexual health services in subAfrica. 2016;1-4. doi:10.1136/2010.193169

9. Central Statistical Agency. Ethiopia Mini Demographic and Health Survey (EMDHS). 2014. doi:10.4269/15-0192

10. Human Development Resource Center. Helpdesk Report: Adolescent Reproductive Health in Ethiopia. 2011.

11. Ministry of Health of Federal Democratic Republic of Ethiopia. National Adolescent and Youth Health Strategy 2016-2020. Addis Ababa, Ethiopia; 2016.

12. Federal Ministry of Health. Gender, Poverty and the Challenge for Adolescents. Ethiopia; 2009.
13. P, Kidanu A, Bantayerga H. Youth Reproductive Health in Ethiopia. 2002. doi:10.13140/2.1.3579.6809

14. WHO and the Partnership for and Child Health. National Reproductive Health Strategy 2014-2018. Geneva, Switzerland; 2014. Available from: http//www.searo.who.int///-2014-2018pdf=1. Accessed September 10, 2018.

15. World Health Organization. Youth and Health Risk. In: Sixty-Fourth World Health Assembly. 2011. 1-4.

16. World Health Organization. Health for the World's Adolescents: A Second Chance in the Second Decade. Geneva, Switzerland: WHO; 2014.

17. Saher S. Breaking the silence: learning about youth sexual and reproductive health in Egypt. 2013.

18. Mbeba RM, Mkuye MS, Magembe GE, Yotham WL, Mellah A, Baptist S. Barriers to sexual reproductive health services and rights among young people in Mtwara district, Tanzania: a qualitative study. Pan Afr Med J. 2012;13(Supp 1):1-6

19. Geary RS, Kahn K, Norris SA. Barriers to and facilitators of the provision of a youth-friendly health services in rural South Africa. 2014June). : 10.1186/1472-6963-14-259

20. Ian S, September K. Getting it right for children and young people overcoming cultural barriers in the NHS service to meet their needs a review by Professor Sir Ian Kennedy September 2010 a summary and critique for BACCH members. 2010, September. 1-5.

21. For S, award the, the of. Access to sexual and reproductive health care services by adolescent girls aged 15-19 years among pastoral communities in Narok Njoki Mbugua Leah (BSc. FND) Department of Community Health Degree of Master of Public Health (Monitoring and Evaluation) in the School of Public Health of Kenyatta. 2015.

22. Ashford L, Makinson C. Reproductive Health in Policy and Practice: Case Studies from Morocco and Uganda. Washington (DC): Ref Bur; 1999.

23. Awusabo-Asare K, Albert MA, Akwasi K-K. Adolescent Sexual and Reproductive Health in Ghana: A Synthesis of Research Evidence. 2004. doi: $10.2307 / 41329750$

24. A, Kassaw T, Hailu G. Level of young people sexual and reproductive health service utilization and its associated factors among young people in Awabel District, Northwest Ethiopia. PLoS One. 2016;11 (3):1-11. doi:10.1371/journalpone 0151613

25. Advocates of Youth. The facts adolescent reproductive health in Nigeria. 1999:24-25. Available from: www.advocatesforyouth.org. Accessed September 15, 2018.

26. Abiodun O, Olu Abiodun O. Sexual and reproductive health knowledge and service utilization among in-school rural adolescents in Nigeria. J AIDS Clin Res. 2016;7:6. doi:10.4172/2155-6113.1000576

27. Context T, Girls A Review of adolescent family planning policies in Malawi. 2017September).

28. Binu W, Marama T, Gerbaba M, Sinaga M. Sexual and reproductive health services utilization and associated factors among secondary school students in Nekemte town, Ethiopia. Reprod Health. 2018;15 (1):1-10. doi:10.1186/s12978-018-0501-z

29. T, Tegegn A, Gelaw Y. | C O M M E N T reproductive health services and intimate response shaping partner violence in Sub-Saharan Africa a pragmatic. Reprod Health. 2012;30:4

30. Zone H, Nations S, Region P. Public health \& and factors affecting adolescents and youth friendly reproductive health services among secondary school students in Hadiya Zone, Southern Nations, Nationalities and People Region, Ethiopia. J Pub Health Safe 2017;2:4

31. A, Fantahun M, Worku A. Original article reproductive health needs of out-of-school adolescents A cross-sectional comparative study of rural and urban areas in northwest Ethiopia. J Health Dev. 2006;20(1):17.

32. A, Syre T, Egata G, Kenay A. Utilization of youth friendly services and associated factors among youth in Harar town, east Ethiopia: A mixed method study. BMC Health Serv Res. 2016;16(1):1-10. doi:10.1186/s12913-016-1513-4 
33. A, Gelaw Y. Adolescent reproductive health services in Jimma city: accessibility and utilization. $J$ Health Sci. 2009;19 (2):91-102. :doi10.4314/v19i269414

34. N, Darega B, Takele A. Reproductive health services utilization and its associated factors among Madawalabu University students, Southeast Ethiopia: cross-sectional study. BMC Res Notes. 2015;8 (1):1-8. doi:10.1186/s13104-015-0975-5

35. AA, Seme A. Reproductive health knowledge and services utilization among rural adolescents in east Gojjam zone, Ethiopia: a community-based cross-sectional study. BMC Health Serv Res. 2014;14(1):1-11. doi: 10.1186/1472-6963-14-138

36. Ansha MG, Bosho CJ, Jaleta FT. Reproductive health services utilization and associated factors among adolescents in Anchar district, East Ethiopia. J Fam Reprod Heal. 2017;11(2):110-118. doi: $10.13031 / 2013.30443$
37. DerSimonian R, Kacker R. Random-effects model for meta-analysis of clinical trials: an update. Contemp Clin Trials. 2007;28 (2):105-114. doi:10.1016/2006.04.004

38. B. Assessment of reproductive health service utilization and associated factors among adolescents (15-19 years old) in Goba town, Southeast Ethiopia. Res. 2015;3(4):203. doi:10.11648/20150304.12

39. Feleke SA, Koye DN, Demssie AF, Mengesha ZB. Reproductive health service utilization and associated factors among adolescents (15-19 years old) in Gondar town, Northwest Ethiopia. BMC Health Serv Res. 2013;13(1):1. doi:10.1186/1472-6963-13-294

40. Negash W, Dessalegn M, Yitayew B, Demsie M, Wagnew M, Nyagero J. Reproductive health service utilization and associated factors: the case of north Shewa zone youth, Amhara region, Ethiopia. Pan Afr Med J. 2016;25Supp 2)3. doi:10.11604/ 2016.25.2.9712

\section{Publish your work in this journal}

Adolescent Health, Medicine and Therapeutics is an international, peer-reviewed, open access journal focusing on health, pathology, and treatment issues specific to the adolescent age group. All aspects of health maintenance, preventative measures and disease treatment interventions are addressed within the journal and practitioners from all disciplines are invited to submit their work as well as healthcare researchers and patient support groups. The manuscript management system is completely online and includes a very quick and fair peerreview system. Visit http://www.dovepress.com/testimonials.php to read real quotes from published authors. 